Complexity, Muddling Through, and Sustainable Forest Management

by

D avid Colander

August 2003

MID D LEBURY COLLEGE ECONO MICS D ISCUSSION PAPER NO. 03-20

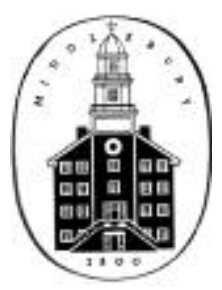

DEPARTMENT OF ECONOMICS

MIDDLEBURY COLLEGE

MIDDLEBURY, VERMO NT 05753

http:/ / www.middlebury.edu/ econ 


\title{
Complexity, Muddling Through, and Sustainable Forest Management ${ }^{*}$
}

\author{
David Colander \\ Middlebury College \\ This paper was prepared as the Invited Luncheon Address at the International Conference on \\ Economics of Sustainable Forest Management
}

In The Worldly Philosophers Robert Heilbroner tells a story of a dinner John Maynard Keynes had with Max Planck, the physicist who was responsible for the development of quantum mechanics. Planck turned to Keynes and told him that he had once considered going into economics himself, but he decided against it-it was too hard. Keynes repeated this story with relish to a friend back at Cambridge. "Why, that's odd," said the friend. "Bertrand Russell was telling me just the other day that he'd also thought about going into economics. But he decided it was too easy." That story captures two typical reactions that students often have to economics. For some it is too easy; for others it is too hard. Both reactions are reasonable.

\section{Two Alternative Stories}

One of the reason economics can be viewed as both easy and hard is that it is a highly complex subject, which, for pedagogical reasons, has to be simplified to a basic story line. Some tangents are allowed, but ultimately those tangents must interweave with the main story line, or they do not appear. I suspect that Planck and Russell differed because they were referring to different story lines.

Russell was thinking of the story line currently used in the micro texts, which is what might be called the efficiency story line. The efficiency story is a story about the state of competition. It is a static story, which nicely fits into a calculus (especially LaGragrangian multiplier or Euler equation) framework. While few principles students completely understand the full efficiency story line, they generally have a sense of a number of examples of it--the effect of taxes, quantity restrictions, price ceilings, and price floors on efficiency--and the way in which the economy adjusts to sudden changes in tastes.

Students also learn that under appropriate conditions individual maximization will lead to social maximization, although, to be honest, few principles students come away from the course with a deep understanding of that. They are usually struggling with the simple individual optimization story. One of the reasons this social maximization story makes an acceptable textbook story is that it does not rule out government action. Externalities can upset that marketbased social maximization, and the government can offset those externalities through appropriate tax policy. Thus, the efficiency story line has the needed neutrality to sell to a wide market. It neither opposes nor favors government action, although the story can be spun in a variety of ways to fit individual instructor's biases.

\footnotetext{
*Parts of this paper come from early drafts of a book I am currently working on with William Brock entitled The Economics of Muddling Through. (Colander and Brock, forthcoming-b) At this point only I am responsible for the arguments presented here.
} 
Many students have a hard time understanding the efficiency story because, even though it is highly simplified, it is still complicated. Since the stories are often told graphically and algebraically, languages that are difficult for many principles students to understand, the language problem makes the story difficult. In fact, many students never get around to learning the ideas of economics; they spend all the time learning math.

This maximization cost/benefit story line, which is a key element of the efficiency story as it relates to policy, is a very useful one for students to learn, and to carry with them for the rest of their lives. Since principles of economics is only one of about 35 courses that make up student's training in college, it seems a reasonable story to teach. But, as with all things, it comes at a cost, and that cost is that many students never are introduced to other important stories that economists could tell. One of those alternative stories involves developments that are currently ongoing in the economics profession--developments to which many of the papers in this volume are contributing. That alternative story line might be called the complexity story line.

The complexity story is a much more complicated story than the efficiency story, and is the story Planck was likely referring to. It is about the process of competition, and is based in a dynamic framework. It is an evolutionary story of an economy operating over time--drifting along on a slowly moving river with occasional rapids, none of which are directly controlled, or controllable. The complexity story is an almost magical story, one in which the invisible hand of the market takes what should be chaos, and turns it into an elegantly complex structure that fits together, not perfectly or efficiently, but sustainably. Patterns and pictures develop out of nowhere. The resulting system is admired not for its efficiency, nor for any of its static properties; the resulting system is admired for its very existence. Somehow the process of competition gets the pieces of the economy to fit together and prevents the economy from disintegrating into chaos. Observed existence, not deduced efficiency, is the key to the complexity story line.

\section{Sustainability and the Two Stories}

I discuss these two stories because they help explain the neglect of issues of sustainability in economics: Sustainability is not discussed much in the texts because you can't neatly weave sustainability into the efficiency story. The efficiency models being taught assume sustainability, as long as the natural resources are available. This means that to bring sustainability into the texts would involve a major interruption to the flow of the current story, an interruption that would likely lose the reader's interest.

A second reason that the term, sustainability, is not used in the texts is that it conveys to many economists an integration of normative judgments into the analysis. Such a normative use of the term involves not only an interruption of the efficiency story, but a complete incompatibility with it. The efficiency story has struggled to keep such normative judgments out of the reasoning process being taught. It is for these two reasons that if you look at the texts you will see very little discussion of sustainability of any type. In fact, among Rust Belt economists (Chicago/Rochester and their satellites) the very mention of the term "sustainable" makes their eyes roll in a signal to other Rust Belt economists that "Here we go again; we are talking with another of those wishy washy environmentalists, who are trying to instill their values on others." 
For Rust Belt economists sustainability simply isn't an appropriate topic of discussion for proper economists. ${ }^{1}$

Sustainability fits much better into the complexity story. In models of complex systems one doesn't talk about equilibrium; one talks about basins of attractions. Within a complex system a "rational choice" is much harder to specify, and even if one can specify it, the systemic forces rewarding "rational choice" are often weaker than they are in simple systems. This means that instead of weaving the story around a predetermined equilibrium that must finally be reached if the system is left to its own devices, the complexity story is woven around the dynamic process through which one basin is reached temporarily, but other forces are building up to push it into another basin; it is a never-ending story.

Generally, complex systems will have no single equilibrium; but instead a collection of possible basins of attraction, with some basins more likely than others. One can only discover the likelihood of certain basins of attraction by considering the evolution of the entire system with either a heuristic or formal simulation. Instead of thinking of equilibrium, one thinks of replicator dynamics, which drive the system forward in a variety of possible ways. By the replicator dynamics I mean the way in which the aggregated decisions of the agents in the system have a tendency to lead to certain outcomes often not foreseen by individual agents, and possibly not predictable by any agents in the system. Because of the multiple paths, and the potential complicated dynamics, complex systems are generally analytically indeterminate. To gain insight into a complex system one must think in an evolutionary framework in which many different paths are possible, some more sustainable than others.

In the complexity story the market isn't desirable because of some grand sense of efficiency, and government isn't seen as an entity that can tweak a market process result in a certain way to achieve efficiency. Because the market is seen as fully integrated with the society, tweaking one aspect of the market process can imply a major change in another aspect - the proverbial butterfly flapping its winds in China can change the weather pattern in the U.S. Sudden shifts of the system from one basin to another become part of the analysis, and thus the sustainability of a particular basin, which in the complexity literature generally goes under the name resilience, becomes an interesting issue.

This complexity story conveys a quite different sense of what is happening to an economy than does the efficiency story. It sees change as an evolutionary process occurring at many levels simultaneously. There are interdependent slow and fast moving variables, and policy is affecting all of them. Since one does not see the effects on the slow moving variables in the short run, short run empirical measures of the effects of policy may be misleading.

The policy problem of complex systems is exponentially complex, and pure theory provides far less guidance than it does in simpler systems. Policy must take account of multiple levels of optimization occurring at different speeds. For example, the selection of a certain policy can change tastes, so any policy built upon current tastes may be less than optimal. Policy that does not take account of the cumulative process of policy and change can miss important

\footnotetext{
${ }^{1}$ Todd Buchholtz in The Armchair Economist (Buchholtz 1993) is a good representative of an excellent Rust Belt economist.
} 
elements of what is really going on. Moreover, in a complex system optimizing likely involves nonlinearities and kinks, making first order conditions of little use in drawing out robust global policy conclusions.

In a complex system resilience, and hence sustainability of the current basin of attraction, becomes a central policy issue. If society likes its current basin of attraction, and believes that it is preferable to other potential basins, maintaining that equilibrium is another societal goal, one that often conflicts with efficiency interpreted the way it is normally interpreted in the textbook efficiency story. For example, it might be efficient to plant a particular type of tree in a forest, but the result of doing so might not be resilient. If a disease attacks that type of tree, it affects all trees in the forest, and the end result can be a complete devastation of the forest. In this case creating a resilient system has a cost in reduced efficiency, used as it is usually used - to mean maximizing output without regard to the distribution of that output. ${ }^{2}$ James Scott (1998) has a nice discussion of how an application of efficiency analysis to forest management in Germany led to serious problems because of ignored resilience issues.

I raise this issue to point out that the way one looks at costs and policy depends on the story being told. For example, within the efficiency story, trade has no cost, and an expansion of trade is seen as an unmitigated good. Within the complexity story, trade, and even efficiency as the term is normally used in the texts, has a cost. Thus, globalization and "efficient" production can reduce the resilience of the system. They can speed the transmission of a pathogen, thereby making an unexpected pathogen potentially fatal to the entire system, rather than keeping pathogens contained geographically. The SARs virus epidemic, which caused the postponement of the conference upon which this volume is based, is an example.

Of course, to say that sustainability becomes a potential concern of the system is not to say that the way in which sustainability is used by researchers is not subject to implicit, unstated value judgments, ambiguity, and assumptions that are not in accord with empirical observations. As I read popular articles on sustainability it is often unclear to me precisely what the authors mean by sustainable. But just because not all individuals who use the term have cleared up the definitional ambiguity, and just because the term does not neatly fit into the efficiency story, does not mean that sustainability is not a relevant topic for economists to consider, and a highly relevant topic for public policy. I believe it is. My point is that to fit sustainability into the economics found in the texts, authors must switch from an efficiency story to a complexity story.

\section{Differences in the Two Stories}

With that background let me reconsider Planck and Russell's different reactions to economics. Judged from the perspective of a Planck, or a Russell, the efficiency story is a piece of cake; it involves elementary algebra and calculus. To Russell that story was too easy to study. The complexity story, however, is formally untellable, and is far more difficult than particle physics. It requires mathematics that was not yet developed in Keynes' time, and is only today beginning to be developed. For Planck, that story was too hard to even contemplate studying.

\footnotetext{
${ }^{2}$ This shorthand use of the term efficiency shows the limited nature of the efficiency story. In a broader sense the term "efficiency" is not the goal; it is a means to a goal; it involves achieving an outside goal as cheaply as possible. If resilience is a goal, then efficiency should include the achievement of resilience in the specification of what is efficient.
} 
The following story told by Brian Arthur of a discussion at the first Santa Fe conference on complexity gives one a sense of why the story is so difficult. At that conference Arthur was discussing the problem of including increasing returns in the economic model with one of the physicists there. The physicist said that increasing returns is like spin rotation and that therefore economics with increasing returns is very much like physics. The physicist went on to say that since there are more atoms than people, physics must be harder than economics. Arthur changed the physicist's view by pointing out that in economics one has an additional complication; to make the analyses comparable one would have to assume that each atom had a will of its own, and that what it was trying to do is to take advantage of the other atom, and thwart any attempt at control. Thus, every time you tried to control them, they modified their spin to make any control more difficult. With that explanation the physicist agreed that economics was much more difficult.

\section{Why the Complexity Story Isn't Told in the Texts}

I am both a textbook author and an economist, so I feel the pull between the two stories. As an economist, I direct all my thoughts toward the complexity story, trying to understand the work that is being done on it. But little of that work shows up in my principles text. There are two reasons why. The first is the sheer complexity of the complexity story. I believe there is a story there, but I'm not sure I can tell that story in a meaningful way to students, or even to myself. A second reason is that I believe the complexity story and apply it to all my decisions. Applied to textbooks, it makes me, and I suspect other authors of successful texts, reluctant to change something that is working. Currently textbooks are working and serving a useful purpose. I believe that the story we are telling in our teaching of economics - the efficiency story--is a useful one for all students to learn; it is far more useful than the stories they learn in most of their other classes. I want every student to come out of college with a strong understanding that there is no such thing as a free lunch. Telling the efficiency story achieves that end, and thus seems justifiable, so it is only reasonable to be hesitant to change from that story.

The underpinnings for a major change in the story economists see themselves studying, and eventually that they will see themselves telling, are, however, currently taking place. As the complexity story develops, it will become more and more tellable, and, as the current texts die out, new texts that make the change to the complexity story will eventually replace the older texts. But I suspect that because the change involves a totally different story line, the change in stories will be a sudden shift rather than a smooth movement. (Colander 2000c) In the meantime, by which I mean the next 20 to 40 years, the real changes will be made in research in particular fields such as forest management. In most of these field areas researchers have already fully mined the efficiency arguments, and have extracted much of the insight from that model. Thus, they have an incentive to explore alternatives, such as the complexity approach.

\section{The Changes Currently Going On in the Profession}

While all the field courses are proceeding on their own path, there is sufficient similarity in the changes that are occurring in the profession to suggest the nature of these changes. It is a change in the allowable assumptions, from the holy trinity of rationality, greed and equilibrium to a broader set of allowable assumptions, which might be called purposeful behavior, enlightened self interest and sustainability. 
The acceptance of these changes by the profession can be seen in a variety of theoretical work, such as work in behavioral economics, evolutionary game theory, agent based modeling, experimental economics, and new institutional economics. Indeed, as I have argued elsewhere (Colander, Holt and Rosser, forthcoming) much of the theoretical work that is considered cutting edge falls into the category of moving away from the holy trinity. The trend is apparent in the allocation of awards in economics. For example, Daniel Kahneman and Vernon Smith recently won a Nobel prize for their work in experimental economics and Mat Rabin won the John Bates Clark medal for work on behavioral economics. Because of these changes today one can no longer describe modern economics as neoclassical economics. (Colander 2000a)

I do not want to overstate how these changes are currently affecting economists. Most economists do variations of what they were taught to do, and so have not changed significantly. "Same economist" research changes only slightly. But the economics profession is not a static group, and so the research also changes with the evolving composition of economists, with younger, newly trained economists coming in, and older economists going out. Thus the evolutionary hiring and retirement process affects research.

As time passes, younger, differently trained, economists replace older economists, and the average image of what economics is and of how one does economics changes. Since the profession replaces itself every 35 years or so, the rate of change is only about $3 \%$ per year. However, even that rate may be an over-estimate of the degree of change in the initial stages of a cycle of change, because most students choose to work with established professors in established methodologies; the newer methodologies and techniques are risky. Initially only a few riskpreferrers choose that path. So, at the beginning of a cycle of change, the rate of change toward a new acceptable approach is smaller than that $3 \%$, probably closer to $1 \%$. However, at some point a critical mass of work is accumulated, a shift point occurs, the new approach becomes the hot approach, and students flock toward it. At that time the rate of change increases to greater than $3 \%{ }^{3}$

\section{Where Are the Changes Leading Us?}

Ultimately I see these changes leading to a change in the basic story we are telling in economics from the current efficiency story told in the texts-the story of infinitely bright agents in information rich environments - to the complexity story-the story of reasonably bright individuals in information poor environments. Another way of describing my thesis is that the vision of the economy will evolve from its previous vision of a highly complex "simple system" to a highly complex "complex system." "Simple systems, no matter how complex, are reducible to a low dimensional set of equations, making it possible to model the system analytically. A complex system is not, and must be represented in another fashion-through simulation, or through insights gained with replicator dynamics. One can never have a full analysis of the entire complex system.

\footnotetext{
${ }^{3}$ That is close to happening in behavioral economics in certain fields such as finance. As Richard Thaler has said, once, people asked what was behavioral finance; now people ask what other type of finance is there. A leading indicator of the changes that are occurring, one looks at the hiring priorities of top schools, and the needs their hiring departments see. In the early 2000s behavioral economics is seen as a hiring priority; experimental economics is not yet a totally accepted hiring priority, and agent based modeling is hardly on the horizon.

${ }^{4}$ For a discussion of what is meant my complex system see Auyang (2000)
} 
Simple and complex systems differ in their micro foundations. Simple systems can be studied from their micro foundations. Complex systems involve emergent properties, and cannot be understood from an analysis of the elements of the components of that system, studied outside the context of the system. There can still be micro foundations, but the microfoundations of complex systems are contextual, and can only be understood in reference to the existing system. Such complex systems are built up in path dependent stages, making individual optimization within such systems history and institution specific. This means that its institutional structure is central to understanding complex systems, and that any assumed rationality must involve some boundedness.

As I stated above, the current steps the profession is taking are minimal, but the ultimate result of these steps is a movement from telling the efficiency story to telling the complexity story in their research and eventually in the texts. The acceptance of this complexity vision of the economy involves a shift in economics far more fundamental than anything associated with the movements away from the holy trinity that the profession has made so far.

These changes will take place because they offer exciting dissertation topics to graduate students and research possibilities for young researchers. As they work on these issues, there will be learning by doing and more of this new work will be done. Work that seems especially promising includes work in behavioral economics, evolutionary game theory, and experimental economics. Behavioral economics is the most developed. It is considering issues such as reference-dependent preferences, the replacement of expected utility with prospect theory, the development of hyperbolic discounting arguments, the formalization of cognitive heuristics, the replacement of theories of self-interest by theories of social preference, and the development of adaptive learning models.

Once one accepts that the behavioral foundations of choice are important, one is directed to experiments, and experimental economics is another expanding area. Experimental economics provides an almost endless set of possible dissertation topics using a methodology that is quite outside the efficiency framework. It gives one a method of choosing among assumptions, and an alternative to statistical empirical testing. Economists still have a long way to come in experimental work, but that work has the possibility of changing economics significantly.

The acceptance of behavioral economics also leads to using evolutionary game theory as the setting for a foundational theory of economics. Evolutionary game theory allows one to redefine how institutions are integrated into the analysis and to develop a social dimension of individuals, which was previously lacking in current textbook story of economics.

\section{Why Now?}

Heterodox and heuristic economists have long argued that economics should deal with broader issues. So the questions arise: Why is the change occurring now? And: Why didn't it occur previously? My answer to these questions is that what has changed is not the recognition that these broader issues are important; that's always been there; what's changed is the belief that economics may have something to bring to bear on these broader questions. The reason is twofold. First, economists now believe that they have something to bring to these questions because of changes in the analytic and computing technology. Second, the efficiency model, 
developed in relation to the holy trinity, has been developed, and the "low hanging fruit" has been picked. Thus, theorists have an incentive to branch out.

From a technical standpoint, the mathematics involved in the efficiency model is really quite simple; they assume away path dependency, non-linear dynamics and many similar complicating features that could well characterize real world processes. A unique equilibrium is no longer likely or supportable as an assumption, which undermines the efficiency vision of how markets lead the economy to a social optimum.

Schumpeter (1957) made the assumption of a unique equilibrium as a necessary component of a science of economics. With the higher level of mathematics being taught in graduate school, and with the greater mathematical sophistication of those entering the profession, that restriction is no longer necessary, which is why these more complicated issues are being explored. By understanding the processes that guide the economy in its evolution one can gain insight into the economy and to the future direction of the economy, even if one does not know what it's ultimate equilibrium will be.

But as soon as one moves to these more complicated mathematical approaches, neat analytic solutions are far less likely to be forthcoming. This leads to a third change that is occurring in the profession, and is likely to be the most significant change in the more distant future. That is the movement from analytics to simulations. The reality is that advances in computing power involve a fundamental change in technology that is reducing the value of deductive theory. If one can gain insight through simulation, one has far less need to gain insight through deductive analytic theory. As long as computing power continues to double every 18 months, agent-based simulation will become more and more important in economist's tool kit, and will eventually replace deductive analytic theory, and the supply/demand framework of the current texts.

In these agent-based models the researcher "grows" an economy, letting simple algorithms describing agent behavior (algorithms developed in behavioral work) compete with one another, and see which wins out. ${ }^{5}$ Agent-based simulations are fundamentally different than simulations designed to solve equations. In agent-based modeling one analyzes the system without any equations describing the aggregate movement of the economy; one simply defines the range and decision processes of the individual actors. Through multiple simulation runs one can gain insight into the likelihood of certain outcomes and of the self-organized patterns that emerge from the model. As computing power becomes cheaper and cheaper, such modeling will likely take over the profession. Ultimately, I see virtual economies being created in which policies are tested to determine their effectiveness in the same way that virtual designs are currently tested.

Is such agent based modeling still economics? I believe it is; it keeps much of standard economics - it sees individuals as purposeful, although the precise nature of purposeful behavior is derived from the model rather than assumed. It assumes individuals interact and trade, and that successful individuals continue; unsuccessful individuals do not. But to be honest, it is likely that

\footnotetext{
${ }^{5}$ For a discussion of agent-based modeling see Robert Axtell and Josh Epstein (1996) and Robert Axelrod (1997).
} 
the simulation based economics will be more social science generally, and fall under a general "cognitive science" discipline.

\section{Policy Implications of the Two Stories}

What relevant policy lessons for students come out of the complexity story is far less clear to me, and I think to the entire profession, than is the fact that the changes are occurring. In thinking about the policy implications of the complexity story, Hayek, following the ideas of complexity, initially pushed the implications too far, and seemed to be saying that there was no room for policy activism - that the economics system should be left alone. ${ }^{6}$ There clearly is some sense of that coming out of the complexity story, but I see simply a more nuanced policy view coming out of the complexity story in which the theory is neutral about general policy prescriptions in the same way that the current textbook efficiency story is neutral. There are reasons for government intervention and reasons for laissez faire in the complexity story. They just are not necessarily the same ones as found in the efficiency story, and they are much harder to pull out of the analysis. Determining a firm foundation for the implications of the complexity story for policy is a long way away.

I have tried to develop that sense of policy nuance in my work on what I call the economics of muddling through (Brock and Colander forthcoming-a,b) which I contrast with the efficiency story's economics of control approach. In the economics of control, one can, at least in principle, state what the optimal action for each agent, and the optimal policy for the policy maker, will be. In the economics of muddling through, specifying the optimal action for the agent and the optimal policy is far beyond the capabilities of the modeler. The best agents can do is to muddle through; similarly, the best policy makers can do is to muddle through.

Instead of controlling the economy, the goal of policy makers is to muddle through as effectively as possible, perhaps improving the workings of the economy in certain specific instances, but with no grand vision that one is going to suggest an optimal policy. In the economics of muddling through there is no such thing as a free lunch, but once in a while you can snitch a sandwich. Policy work is designed to snitch as many sandwiches as one can. I am pleased with this "muddling through" policy story, and believe that eventually it will be the way economists think of themselves and policy. But it is still in development and is not yet ready for prime time.

I do not claim that muddling through is a breakthrough in our understanding of economic policy issues; it simply is recognition of the limitations of our knowledge of the effects of economic policy. In nuanced discussions among good economists, the limitations of the current theory are well known, and the policy implications of any model they develop have always been for more nuanced, and considered in a much broader framework, than in policy discussions found in the texts. However, to make the story simple enough for the texts, the policy presentation has to be simplified, and it is that simplified version that students learn, which reporters present as economist's views, and which economists sometimes fall back on when they are pushing an idea, or simply being lazy.

\footnotetext{
${ }^{6}$ In his later writings, he modified these views and focused more on the importance of institutions and law. For a discussion see contributions on Hayek in Colander (2000b).
} 
Muddling through is conducting policy without an ultimate set of plans. So not only are the agents of the new economics operating in an information poor environment, so too are the policy makers. In such a situation policy becomes problem driven, not theory driven. Economics becomes not a single theory that guides policy, but a set of tools - statistical tools, modeling tools, and heuristic tools--that when incorporated with knowledge of the institutional structure can help the policy maker achieve the solution to problems posed by agents in the system.

This muddling through approach is a quite different view of policy economics than the view that is presented in the texts, where economists are the holders of knowledge of what policies will achieve global efficiency. In muddling through global efficiency is beyond what one can hope to achieve. One can still talk about efficiency, but it is defined locally in relation to existing institutions, and means producing what one is currently producing within existing, or only slightly modified institutions, at the lowest cost. It is useful only in analyzing incremental change, where issues of sustainability are minimal. Used in this limited sense its implicit assumption that one's normative ends are little changed from previously, and that they can therefore be left implicit, can be seen as a reasonable simplification.

Broader, less locally defined efficiency, is much more difficult to either define or use in policy discussion. Policy work in muddling through must make ones goals and assumptions clear. Thus, more generally, in muddling through efficiency is not a goal, but a condition imposed by the analysis about the costs of achieving whatever goal has been specified. It is achieving given ends as cheaply as possible, and only has meaning in regard to those ends. In this muddling through framework you hire an economist, tell him or her your goals, and he or she will bring his or her expertise in modeling and data analysis to help achieve those goals at the least possible cost.

The textbooks will not be telling the story of muddling through for a long time; it is too radical a change in vision. Initially, changes that are least challenging to the textbook story will find their way into the texts. The field of behavioral economics that is exploring the meaning of the "purposeful behavior" assumption is offering the type of modifications that will show up in the texts soon. These modifications offer a slight change in the policy prescriptions that flow from the analysis. An example of what I have in mind is Cass Sunstein and Richard Thaler's (forthcoming) concept of "libertarian paternalism." 7 It proposes a set of policies that are consistent with the standard economic policies prescriptions that follow from the efficiency story, but which take into account agent's ill-formed preferences, one of the insights that follows from behavioral economic work.

These ill-formed preferences mean that individual's choices influenced by default rules, and libertarian paternalism is designed to take advantage of this fact. For example, say the policy maker believes that individuals will be better off with more forests in the world, and that a policy allows individuals to direct a part of their taxes to forests. By making that policy option the default option, and requiring the individual to default out of the program, rather than requiring the individual to choose to be in the program, the policy maker can increase participation in the program significantly. Doing so does not take away the individual's choice since the individual has the same choice in both situations, but the behaviors will be quite different.

\footnotetext{
${ }^{7}$ I expect to include a discussion of the libertarian paternalism in my next edition.
} 
Applying even this small implication of behavioral economics to policy is a major step. It means that economists must accept that normative judgments become part of the policy process. But a full acceptance of the policy implications is a much larger step. If tastes are endogenous, then normative issues become a central role in economic policy and cannot be escaped or ignored.

\section{Conclusion: Economics and Sustainable Forestry}

Let me conclude with a few brief comments about the implications I see this shift having for forestry research. As I see it, many people have a sense that it may be a good goal for society to have the economy move to an equilibrium that is characterized by more of our land devoted to forests, than they believe is likely to be the case under existing institutions. While I tend to agree with that normative view, I also believe that what one means by forest is often ambiguous. What can be called a forest, and how to weight different types of forests, are difficult problems and can account for much confusion in the debate. In dealing with this debate the efficiency story is not especially helpful, because it excludes many of the issues upon which the debate is based.

By being more open to alternative assumptions, the complexity approach to economics brings economists back into the theoretical and policy debate. That, in my mind is a plus for everyone involved. Thus, I disagree with those economists who fear this movement; to fear it means that one does not believe that the policy insights of economics will be able to compete with the insights from other disciplines and from other approaches. I believe that they are strong enough. The complexity approach gives up the pillars upon which our welfare economics is built and in doing so it gives up the almost theological sense of what is right that is often associated with that view. In doing so it loses some influence. But by entering the debate, and letting economic ideas procreate with other ideas, it gains, and becomes stronger.

In the complexity approach we will not have theory to rely upon to say what policy is right or wrong. But we will have tools that can add insights about how to create the desired ends. Will certification actually increase the amount of forests, or will it have unintended effects? Are there other ways to achieve that goal? Can trees be made into an "image good" so that individuals can gain pleasure from the existence of trees? Can land trusts be expanded, so that people have a method of changing their demand for forests into a real demand? Can we structure institutions so that our society is more forest friendly? For example, I have often wondered about the wastefulness of cemeteries and the granite monuments to death that somehow have been built into our culture. Why couldn't we have found a basin of attraction that, whenever a person dies, instead of being buried in a cemetery, that person is buried in a sacred cemetery forest, which will be kept for generations and generations. I'm not sure what the answers to these questions are, but in asking them, and others like them, the research in forestry is moving to the new complexity story approach to economics that will eventually take over the way economics is done. 


\section{Bibliography}

Auyang, Sunny Y. 2000. Foundations of Complex-System Theories in Economics, Evolutionary Biology, and Statistical Physics

Axelrod, R. 1997. The Complexity of Cooperation, Agent Based Models of Competition and Collaboration, Princeton University Press: Princeton.

Axtell, R. and Josh Epstein. 1996.Growing Artificial Societies from the Bottom Up MIT and Brookings

Brock, William and David Colander 2000 "Complexity and Policy" in D. Colander ed. The Complexity Vision and the Teaching of Economics, Aldershot, UK Edward Elgar.

Brock, William and David Colander forthcoming-a. "Complexity, Pedagogy, and the Economics of Muddling Through" in Salizar (ed) The Economics of Complexity. Aldershot, UK Edward Elgar.

Brock, William and David Colander. forthcoming-b Muddling Through Princeton University Press (manuscript in process)

Buchholz, Todd. 1993.The Armchair Economist. Free Press.

Colander, David. 1991. Why Aren't Economists as Important as Garbagemen? Sharpe Publishing,

Colander, David. 2000a. "The Death of Neoclassical Economics," Journal of the History of Economic Thought, 22(2), 127-43.

Colander, David. 2000b (editor) Complexity and the History of Economic Thought. New York. Routledge Publishers.

Colander, David. 2000c. (editor) The Complexity Vision and the Teaching of Economics. Edward Elgar.

Colander, David, Richard Holt, and Barkley Rosser. forthcoming. The Changing Face of Economics. University of Michigan Press. Lansing, Michigan.

Heilbroner, Robert. 1953. The Worldly Philosophers. Simon and Schuster.

Lerner, Abba. 1944. The Economics of Control. Macmillan.

Schumpeter, Joseph. 1957. History of Economic Analysis

Scott, James 1998. Seeing Like a State. Yale University Press. New Haven.

Sunstein, Cass, and Richard Thaler. forthcoming. "Libertarian Paternalism" Chicago Law Review 